\title{
La Derogación de Normas Jurídicas y Principios de Solución de Antinomias*.
}

\author{
The Repeal of Legal Norms and the \\ Principles for the Solution of Antinomies
}

\author{
Dr. Juan Francisco Guerrero** \\ Pontificia Universidad Católica del Ecuador
}

Infomación del Artículo

Original - Ruptura, 2020

Artículo recibido / Received: 5 de octubre, 2020

Artículo aceptado / Accepted: 2 de diciembre, 2020

\section{Citación}

Guerrero, J. (2020). La Derogación de Normas Jurídicas y Principios de Solución de Antinomias. Revista Ruptura Asociación Escuela de Derecho PUCE. Edición 2020, p (227-252).

DOI: $10.26807 /$ rr.vi02.30

Resumen: El presente artículo analiza la naturaleza de la derogatoria tácita de las normas jurídicas y explica por qué esta no conlleva la pérdida de vigencia de la norma, sino la generación de una antinomia. Sobre esta base, se abordan los diferentes principios y criterios de solución de antinomias aplicables en el Ecuador: (i) el principio de jerarquía; (ii) el principio de competencia; (iii) el principio

* El presente artículo ha sido elaborado con la colaboración de María Yépez Idrovo en calidad de investigadora.

** Abogado por la PUCE es especialista superior en derecho procesal por la UASB, tiene una certificación superior en derecho constitucional por la PUCE. Actualmente se desempeña como docente en derecho procesal y constitucional en grado en la Pontificia Universidad Católica del Ecuador y Universidad San Francisco de Quito y en posgrado en la Universidad Andina Simón Bolívar, sede Ecuador. 
de especialidad; y, (iv) el principio cronológico. Una vez analizados estos criterios, se busca establecer cuál es el orden de prelación con el que deberían ser aplicados por el intérprete.

Palabras clave: Derogación, derogatoria tácita, solución de antinomias, interpretación jurídica, norma jurídica.

\begin{abstract}
This paper addresses the nature of the implied repeal of legal norms and explains why it does not entail the loss of validity of the norm, but rather the generation of an antinomy. On this basis, this investigation analyzes the different principles and criteria applicable in Ecuador to solve antinomies: (i) the hierarchy principle, (ii) the competence principle, (iii) the specialty principle and (iv) the chronological principle. Once these criteria have been analyzed, this article aims to establish the order in which they should be applied by the interpreter.
\end{abstract}

Keyword: Repeal, implied repeal, antinomy solution, juridical interpretation, legal norm

\title{
Introducción
}

En más de una ocasión, criterios claramente errados o desfasados son repetidos sistemáticamente hasta convertirse en verdades incuestionables.

El presente artículo, además de aclarar ciertos conceptos básicos necesarios para realizar cualquier ejercicio interpretativo jurídico, procura desmitificar dos cuestiones que de manera constante se escuchan, incluso, entre quienes tienen una amplio recorrido en el ámbito jurídico ecuatoriano y exponer un punto de vista diferente, más acorde a la normativa constitucional vigente: a) para resolver una antinomia, en primer lugar, se debe considerar el principio de competencia, en virtud del cual, una norma jerárquicamente inferior puede llegar a prevalecer sobre una norma superior; y, b) las normas y preceptos del Código Civil ecuatoriano, que es una ley ordinaria de derecho privado, no pueden ser considerados como 
parámetros absolutos e infalibles para interpretar y solucionar antinomias, incluso en el ámbito del derecho público.

\section{La derogación de normas jurídicas en el Ecuador}

Una norma se encuentra vigente cuando "rige efectivamente la convivencia social en un lugar determinado, ya sea por cumplimiento voluntario de la población o en virtud de ser aplicada por los funcionarios competentes (en definitiva los jueces)" (Torré, 2009, p.252). Por lo dicho, la pérdida de vigencia implica que la norma ya no sea aplicada a las situaciones de hecho que regulaba y, por ende, que deje de generar efectos jurídicos.

Una norma puede perder vigencia formal a través de dos mecanismos: (i) una declaratoria de inconstitucionalidad que, conforme al artículo 96 numeral 1 de la Ley Orgánica de Garantías Jurisdiccionales y Control Constitucional (en adelante LOGJCC), genera que "ninguna autoridad podrá aplicar el contenido de la disposición jurídica”; y, (ii) una derogatoria.

La derogación de una norma implica un acto de voluntad legislativa, implícito o explícito, que provoca que la norma no pueda aplicarse para situaciones jurídicas futuras que se produzcan con posterioridad a su derogatoria. En el caso concreto de las normas jurídicas legales (leyes), para que éstas puedan ser derogadas, requieren de la expedición de otra ley, es decir, que no se puede derogar una norma jurídica legal a través de una norma infra legal ${ }^{1}$.

La derogación de una disposición normativa puede ser de dos ti-

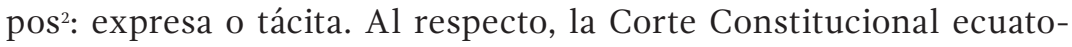
riana ha dicho:

1 Lo dicho es una evidente aplicación del principio en virtud del cual "las cosas en Derecho se deshacen como se hacen".

2 Sin embargo, en países como Colombia, la Corte Constitucional ha reconocido la existencia de un tercer tipo de derogatoria, denominada "orgánica", aun cuando 
[...] la derogación de una norma consiste en dejarla sin efecto; generalmente, debido a la aparición de una nueva norma jurídica que hace perder su vigencia a la anterior. Existen dos tipos de derogación: la expresa y la tácita. La primera es aquella en la que la norma posterior proclama que revoca la que le precede; y, la segunda, nace a partir de la incompatibilidad entre la nueva norma y las disposiciones de la antigua (Sentencia No. 001-13-SIA-CC, 2013, 27) (énfasis añadido).

De lo dicho se desprende que la derogatoria expresa se produce cuando una norma posterior incluye en su texto una declaración explícita en el sentido de que una norma anterior pierde su vigen$\mathrm{cia}^{3}$. Por su parte, la derogatoria tácita se produce cuando la norma posterior no incluye una declaración explícita en cuanto a la pérdida de vigencia de la norma anterior, pero su contenido es incompatible con el contenido de la norma preexistente.

Es importante señalar que por cuestiones de seguridad y certeza jurídica siempre será preferible que la derogación de una norma opere

también se ha dicho que la misma puede ser asimilada a una especie de derogatoria tácita. En este orden de ideas, la Corte Constitucional colombiana ha señalado que: “[...] en cuanto al procedimiento de pérdida de vigencia, el ordenamiento positivo distingue entre la derogatoria expresa y la derogatoria tácita. La primera se produce cuando explícitamente una nueva disposición suprime formalmente a una anterior; mientras que, la segunda, supone la existencia de una norma posterior que contiene disposiciones incompatibles con aquella que le sirve de precedente. A estas categorías se suma la denominada derogatoria orgánica, en algunas ocasiones identificada como una expresión de derogatoria tácita, la cual tiene ocurrencia en aquellos casos en que es promulgada una regulación integral sobre una materia a la que se refiere una disposición, aunque no haya incompatibilidad entre sus mandatos" (Sentencia C-668/14, 2014, párr. 6.3.1) (énfasis añadido).

3 Un ejemplo de derogatoria expresa es la disposición derogatoria primera del Código Orgánico General de Procesos, que dispone: “Deróguese el Código de Procedimiento Civil, codificación publicada en el Registro Oficial Suplemento No. 58 de 12 de julio de 2005 y todas sus posteriores reformas". 
de forma expresa ${ }^{4}$. Sin embargo, es prácticamente imposible que el legislador pueda prever y contemplar todas las normas que una nueva disposición jurídica va a afectar. Al respecto, la Corte Constitucional colombiana ha señalado que sostener que la derogación siempre debe ser expresa implicaría exigirle al legislativo que "confronte cada nueva ley con el resto del ordenamiento", lo cual resulta en "una dispendiosa labor que no tiene razón de ser" (Sentencia C-159/04, 2004). Por lo mismo, es claro que la denominada derogatoria tácita es una realidad que se ha presentado y que se va a seguir presentando.

\section{La derogatoria tácita: ¿pérdida de vigencia de la norma o generación de una antinomia?}

Si bien no existe duda de que la derogatoria expresa causa que la norma derogada pierda vigencia, cuando se produce una derogatoria tácita existe debate en cuanto a si la consecuencia de tal tipo de derogatoria es la pérdida de vigencia de la norma o la generación de una antinomia normativa que debe ser resuelta a favor de la norma posterior.

Respecto del debate referente a los efectos de la derogatoria tácita, la doctrina ha señalado lo siguiente:

[...] la derogación expresa hace cesar la vigencia de las disposiciones jurídicas. La derogación tácita, por el contrario, ya se conciba en clave de mera regla de preferencia, de derogación o de invalidez sobrevenida, termina resolviéndose en un problema de interpretación que, sobre todo allí donde no existen mecanismos fuertes de unificación jurisprudencial, puede constituir una seria amenaza para la certeza del Derecho y para la igualdad en su aplicación. Al final, por tanto, la derogación tácita plantea un problema (Gascón, 1994, p.858) (énfasis añadido).

4 Lo mencionado seguramente llevó al constituyente ecuatoriano a incluir el artículo 136 de la Constitución de 2008, una disposición que exige que todo proyecto de ley incluya "la expresión clara de los artículos que con la nueva ley se derogarían o se reformarían", bajo el apercibimiento de no ser admitido a trámite el proyecto. 
El problema que plantea la interpretación de los efectos de la derogatoria tácita es sumamente relevante. Así, si se acepta que los efectos de la derogatoria tácita son los mismos que los de la derogatoria expresa, aquello implicaría que la norma anterior, en ambos casos, pierde su vigencia y es excluida del ordenamiento jurídico del país; mientras que si se acepta que lo que se genera es una antinomia, ambas normas conservarían su vigencia y convivirían en el ordenamiento jurídico, correspondiéndole al intérprete solucionar la antinomia generada.

Por ejemplo, si la Ley A deroga tácitamente a Ley B y se acepta que la derogación tácita tiene los mismos efectos que la expresa, aquello implicaría que la Ley B es excluida del ordenamiento jurídico y cesa su vigencia. Por el contrario, si se hace una distinción en cuanto a los efectos de la derogación tácita frente a la expresa, la Ley B continuaría vigente, pero se produciría una antinomia frente al contenido de la Ley A, la cual debería ser dilucidada por el intérprete.

En nuestro criterio, el afirmar que los efectos de la derogatoria tácita son los mismos que la derogatoria expresa resulta inexacto. Es necesario recalcar que el que una norma haya sido derogada tácitamente implica que se ha expedido una norma posterior, cuyo contenido resulta incompatible con ella. A raíz de esta incompatibilidad entre ambas normas, se genera una antinomia, que debe resuelta por el intérprete a quien le corresponda conocerla. Por lo tanto, resulta claro que una norma que ha sido derogada tácitamente continúa formando parte del ordenamiento jurídico y, más bien, genera un problema de interpretación. En este sentido, la doctrina ha dicho que:

La derogación tácita requiere ser declarada. Tal declaración -que generalmente emana de un órgano jurisdiccional o un órgano aplicador del Derecho-importa un acto de interpretación al caso particular.

El profesor chileno, Antonio Bascuñán, confirma que la derogación que se produce por la aplicación del criterio cronológico es la derogación tácita. A su juicio, la derogación tácita se produce cuando el órgano que debe resolver un caso, y debe fundar su decisión sujetándose al derecho vigente, constata que éste contiene dos soluciones distintas para ese caso, incompatibles entre sí. En opinión del mismo autor, la 
derogación tácita de la ley anterior no es el efecto de un acto realizado en ejercicio de una potestad normativa, sino los efectos de un complejo de reglas que gobiernan el ejercicio de la potestad jurisdiccional. Estas reglas obligan al órgano adjudicador a seleccionar de una manera determinada la norma aplicable al caso. Por tal motivo, la derogación tácita de la ley anterior es constatada y declarada por el tribunal en la fundamentación de su sentencia. Por eso supone un acto interpretativo de la norma anterior y la posterior, que identifique sus respectivos sentidos y constate su incompatibilidad entre sí (Henríquez, 2013, pp.468-469) (énfasis añadido).

De lo dicho se desprende que la derogatoria tácita de una norma no se puede declarar a través de un acto normativo general ${ }^{5}$. Se trata, por el contrario, de la consecuencia de un ejercicio interpretativo en el cual, la autoridad a la que le corresponde aplicar la norma verifica que existe otra posterior que la contradice $y$, en tal virtud, deja de aplicar la norma anterior.

En el Ecuador, no existe una norma jurídica que le atribuya a alguna autoridad o entidad pública la competencia para declarar derogada tácitamente una disposición jurídica con efectos generales ${ }^{6}$. Sin embargo, a través de los precedentes vinculantes de la Corte Nacional de Justicia ${ }^{7}$ y de las decisiones de la Corte Constitucional $^{8}$, se podría obtener una decisión jurisdiccional que, luego del

5 Si se declara derogada una norma a través de un acto normativo general, la derogación ya no sería tácita y se convertiría en expresa.

6 El único ejercicio interpretativo que tiene efectos generales y obligatorios en materia legal se presenta cuando la Asamblea Nacional emite una ley interpretativa. No tengo conocimiento de que en el Ecuador se haya emitido una ley interpretativa en la cual se declare derogada tácitamente una norma. Sin embargo, desde mi punto de vista, en ese caso estaríamos frente a una derogatoria expresa, por lo expuesto en el pie de página precedente.

$7 \quad$ El artículo 185 de la Constitución prevé el procedimiento para que la Corte Nacional de Justicia emita una jurisprudencia obligatoria.

8 El artículo 436 numeral 1 de la Constitución establece que las decisiones de la Corte Constitucional tendrán carácter vinculante. 
correspondiente ejercicio interpretativo, declare derogada tácitamente una disposición. Además, el hecho de que no exista ninguna otra autoridad u órgano público que esté en la capacidad de declarar tácitamente derogada con efectos generales y obligatorios una disposición normativa no es incompatible con que, en el ejercicio de sus atribuciones, una autoridad pública pueda establecerlo para un caso en concreto.

Lo dicho implica que una disposición jurídica que señala que una determinada ley no podrá ser derogada tácitamente, es inútil, ineficaz y carente de relevancia, pues por disposición normativa no se puede impedir o prohibir la existencia de antinomias. Así, cuando el legislador aprueba y promulga una nueva norma legal de cualquier tipo o especie, está expuesto a que ésta se encuentre en contradicción con otras normas preexistentes, y ninguna disposición legal elimina ese riesgo innato a la tarea legislativa. Aunque sería ideal que el legislador, al expedir una norma, revise todo el ordenamiento jurídico y verifique que esta no contradiga ninguna disposición vigente, como quedó señalado, aquello es fácticamente imposible.

Incluso, el sostener que el legislador no puede incurrir en antinomias por existir una ley que prescriba que no es susceptible de derogación tácita, podría considerarse una postura contraria a las facultades legislativas y jurisdiccionales otorgadas constitucionalmente a la Función Legislativa y Función Judicial, respectivamente. En este sentido, en el ordenamiento jurídico ecuatoriano existen varias disposiciones -inclusive de carácter constitucional- que permiten resolver eventuales antinomias, las cuales demuestran que se contempla expresamente la posibilidad de que éstas se generen y que, por ende, es ineficaz cualquier disposición normativa que pretenda desconocerlas. Además, afirmar que una determinada ley no puede ser derogada tácitamente, equivale a sostener que el legislador se encuentra impedido de promulgar normas que contradigan dicha ley, lo cual: (i) resulta imposible de prever hasta que se produzca una situación fáctica concreta que evidencie la existencia de una antinomia; 
y, (ii) limita inconstitucionalmente la potestad legislativa que está atribuida al legislador'.

En este orden de ideas, la doctrina ha sido clara en cuanto a que es imposible prever todas las antinomias que se pueden generan con la nueva legislación, al sostener que:

[...] la incompatibilidad entre normas depende del significado que se atribuya a las disposiciones normativas promulgadas por los distintos órganos normativos. Por ello, es imposible conocer a priori qué antinomias se van a producir al promulgar una disposición nueva: porque no pueden determinarse a priori las normas ya existentes en el sistema jurídico, porque no pueden determinarse a priori las normas que se incorporan al sistema por medio de la nueva disposición, y porque, en consecuencia, no pueden determinarse a priori los conflictos que pueden surgir entre las normas anteriores y las nuevas. Por ello, es importante distinguir entre las distintas técnicas que los poderes normativos pueden utilizar para sustituir una norma por otra, es decir para derogar normas ya existentes y promulgar otras nuevas en su lugar (Ezquiaga, 2010, pp.28-29) (énfasis añadido).

El que una ley contenga una disposición en el sentido de que solamente puede ser modificada por otra ley dictada expresamente para tal fin, no implica que sus disposiciones estén blindadas de enfrentar eventuales contradicciones con otras normas, producto de preceptos jurídicos promulgados con posterioridad a su vigencia. Así, independientemente de su contenido, ninguna norma jurídica puede estar exenta de contradicciones con otras normas. Por lo tanto, resulta erróneo afirmar que una norma no puede ser derogada tácitamente,

9 Al respecto, es importante mencionar que la Constitución de 2008, de forma expresa, señala que cuando un proyecto de ley urgente en materia económica es publicado como decreto-ley, este puede ser reformado o derogado por la Asamblea Nacional, sin contemplar restricciones para una eventual derogatoria tácita (art. 140). Por lo tanto, en virtud del principio "cuando el legislador no distingue, no le es lícito al intérprete hacerlo", no es admisible aceptar que mediante una ley, se restrinja una potestad constitucionalmente otorgada a la función legislativa. 
pues como ha quedado demostrado, aquello equivale a sostener que la norma no es susceptible de contradicción por parte de otras disposiciones. A continuación, examinaremos la forma en que se deben resolver las inevitables contradicciones (antinomias) que existen en el ordenamiento jurídico.

\section{Criterios de solución de antinomias normativas en el Ecuador}

La antinomia se presenta cuando existen dos normas que, frente a una misma situación fáctica, contemplan consecuencias jurídicas diversas e incompatibles entre sí. La actividad legislativa genera antinomias, pues como quedó indicado, es fácticamente imposible que en un país de tradición romano germánica ${ }^{10}$, el legislador verifique toda la normativa vigente a fin de asegurarse que la nueva normativa que pretende expedir no va a contradecir ninguna norma preexistente $^{11}$. De hecho, aunque hiciese el esfuerzo por hacerlo, resultaría imposible que se plantee todas las hipótesis fácticas de aplicación de la distinta normativa en la cual eventualmente se podría generar una antinomia. Tan es así, que la doctrina ha señalado que "las antinomias son una consecuencia natural del dinamismo de los sistemas jurídicos", pues el "conjunto de normas que llamamos Derecho positivo es el fruto de actos de producción normativa sucesivos en el tiempo y que responden además a intereses e ideologías heterogéneas" (Prieto, 2002, p.97).

De lo dicho queda claro que la antinomia es sobreviniente a la actividad legislativa, es decir, que se produce una vez que una determinada norma ha sido promulgada y el intérprete evidencia que es incompatible con otra norma que también se encuentra vigente en el ordenamiento jurídico. Por ello, la inclusión por parte del legislador,

10 Es decir que pertenece al sistema jurídico de derecho continental europeo, cuya fuente de derecho principal es la legislación.

11 Es interesante señalar que, al 23 de septiembre de 2020, el sistema legal LEXIS certifica la existencia de 24.884 cuerpos legales vigentes en el Ecuador. 
en un cuerpo normativo, de fórmulas absolutas en cuanto a que determinada ley prevalecerá sobre otras -incluso que se promulguen en el futuro y cuyo contenido se desconoce-, si bien es común en nuestro ordenamiento jurídico, es irrelevante y no tiene un efecto práctico concreto. Es al intérprete, que en muchos casos es un órgano jurisdiccional, a quien le corresponde dilucidar cuál de las normas en conflicto prevalece sobre la otra, en función de los principios de solución de antinomias previstos en la legislación.

Ahora, como quedó señalado en el acápite anterior, la derogatoria tácita enfrenta al intérprete a una antinomia que debe ser dilucidada. Lo que debe hacer el intérprete frente a esta antinomia es escoger a una de las normas en conflicto por sobre la otra. Para ello, existen los siguientes criterios o principios: (i) jerarquía; (ii) competencia; (iii) especialidad; y, (iv) cronológico ${ }^{12}$.

\section{Principio de jerarquía}

El principio de jerarquía es una consecuencia de que el ordenamiento jurídico sea una estructura escalonada. Este principio implica que las normas superiores, más cercanas a la cúspide de la estructura, prevalecen sobre las normas inferiores, más cercanas a la base.

La estructura escalonada del ordenamiento jurídico está directamente relacionada con el principio de creación y aplicación del derecho, en virtud del cual "sólo es posible aplicar una norma, creando otra norma más restringida que la aplicada, es decir, creando dentro del marco de posibilidades establecido por aquélla" (Torré, 2009, 211). Por ello, no es posible que la norma creada contradiga a la norma cuya aplicación le dio origen.

12 Es importante señalar que en la doctrina no existe unanimidad en cuanto a los criterios para resolver antinomias, sin embargo, los cuatro criterios enunciados están contemplados en el artículo 3 numeral 1 (Reglas de solución de antinomias) de la LOGJCC. 
Por todo lo expuesto, en caso de contradicción entre dos normas de diferente jerarquía normativa, prevalecerá la superior frente a la inferior. En el caso del Ecuador, la jerarquización de las normas jurídicas se encuentra en el artículo 425 de la Constitución ${ }^{13}$ y es esta norma la que el intérprete deberá aplicar para resolver una eventual antinomia entre normas de distinta jerarquía.

\section{Principio de competencia}

El ordenamiento jurídico, especialmente en la Constitución, establece ciertas materias que deben ser reguladas por una determinada especie de norma jurídica (reserva normativa).

En virtud de lo indicado, cuando existe una contradicción entre dos normas jurídicas de diversa especie, prevalece la norma que tiene competencia para regular la materia, es decir, aquella norma a la que la reserva normativa -contenida en una tercera norma jerárquicamente superior a las normas en conflicto- le faculta a regular esa situación ${ }^{14}$.

Resulta claro que la aplicación del principio de competencia depende de la existencia del principio de jerarquía, pues el primero solamente será aplicable en un sistema en el cual una norma superior

13 Art. 425.- "El orden jerárquico de aplicación de las normas será el siguiente: La Constitución; los tratados y convenios internacionales; las leyes orgánicas; las leyes ordinarias; las normas regionales y las ordenanzas distritales; los decretos y reglamentos; las ordenanzas; los acuerdos y las resoluciones; y los demás actos y decisiones de los poderes públicos [...]".

14 Por ejemplo, en la Constitución de 2008, existen, entre otras, las siguientes reservas normativas: (i) la reserva de ley orgánica prevista en el artículo 133; (ii) la reserva de ley prevista en el artículo 132; y, (iii) la reserva de normas regionales prevista en el artículo 262. En caso de existir una contradicción (antinomia) entre este tipo de normas, deberá determinarse la materia en la cual se produce la antinomia y verificar a cuál de los tipos de normas mencionadas le corresponde regularla, a fin de establecer la norma aplicable al caso. 
a las dos en conflicto establezca una reserva normativa que permita resolver la antinomia. En este sentido, Guastini afirma que el principio de competencia es "parasitario del principio jerárquico", en la medida que "[1]a reserva de competencia a favor de una determinada fuente A es "vinculante" para otra fuente B si, y sólo si, está dispuesta por una tercera fuente $C$ que está supraordenada a la fuente A y a la fuente B" (1999, p.440). Caso contrario, señala este mismo autor, "la invasión de parte de la fuente $\mathrm{B}$, de la esfera de competencia atribuida a la fuente A, no sería causa de invalidez de las normas provenientes de la fuente B" (Guastini, 1999, p.440). En el Ecuador, las reservas normativas en materia de leyes se introdujeron en la codificación constitucional de 1998, cuando se incorporó una reserva de ley orgánica máxima ${ }^{15}$ y una reserva de ley ordinaria mínima ${ }^{16}$. En caso de contradicción entre una ley ordinaria y una ley orgánica, el Tribunal Constitucional señaló que debía prevalecer aquella cuya reserva normativa le habilitaba para regular la materia en la cual se producía la antinomia (Resolución No. 030-2003-TC, 2003).

La incorporación de la categoría de "leyes orgánicas" en nuestra legislación ocasionó una distorsión, pues los legisladores consideraban que la ley orgánica dotaba de una mayor relevancia a la materia regulada, por lo que se aprobaron varios cuerpos normativos con el carácter de orgánicos que no correspondían a la reserva normativa constitucionalmente establecida para dicho tipo de normas ${ }^{17}$

15 El artículo 142 de la codificación constitucional de 1998 contenía una enumeración taxativa de las materias que debían ser reguladas a través de una ley orgánica. Se trataba entonces de una reserva máxima, pues fuera de las materias enumeradas en dicho artículo, ninguna otra podía ser regulada por ley orgánica.

16 El artículo 141 de la codificación constitucional de 1998 contenía una enumeración ejemplificativa de las materias que debían ser reguladas a través de una ley ordinaria. Se trataba, por tanto, de una reserva mínima, pues no excluía el que otras materias no previstas en dicho artículo, puedan ser reguladas también por medio de una ley ordinaria.

17 Ejemplos de lo señalado, entre otras varias leyes, son: Ley Orgánica de Responsabilidad, Estabilización y Transparencia Fiscal, publicada en el Registro Oficial No. 589 de 4 de junio de 2002; Ley Orgánica de la Corporación Financiera Nacional, 
Por su parte, la Constitución de 2008 diluyó la diferencia entre leyes orgánicas y ordinarias. Además de no establecer una diferencia formal, existen inconsistencias al momento de la formulación de las reservas normativas. En consecuencia, es complejo establecer su diferencia material, pues hay materias que se encuentran incluidas en ambas reservas, es decir, que podrían ser reguladas tanto por leyes ordinarias como por leyes orgánicas. Así, los numerales 1 y 4 del artículo 132 de la Constitución ${ }^{18}$-norma que regula a la reserva de ley de forma generaltienen un texto prácticamente idéntico al contenido en los numerales 2 y 3 del artículo 133 -norma que establece una reserva de ley orgánica${ }^{19}$. De la similitud entre ambas normas se desprende que la Constitución

publicada en el Registro Oficial No. 387 de 30 de octubre de 2006; Ley Orgánica de Educación Superior, publicada en el Registro Oficial No. 77 de 15 de mayo de 2000 y dotada de la calidad de orgánica mediante Resolución Legislativa No. 22-058 publicada en el Registro Oficial No. 280 de 8 de marzo de 2001; Ley Orgánica de Defensa del Consumidor, publicada en el Registro Oficial No. 116 de 10 de julio de 2000.

Art. 132.- "La Asamblea Nacional aprobará como leyes las normas generales de interés común. Las atribuciones de la Asamblea Nacional que no requieran de la expedición de una ley se ejercerán a través de acuerdos o resoluciones. Se requerirá de ley en los siguientes casos: 1. Regular el ejercicio de los derechos y garantías constitucionales. 2. Tipificar infracciones y establecer las sanciones correspondientes. 3. Crear, modificar o suprimir tributos, sin menoscabo de las atribuciones que la Constitución confiere a los gobiernos autónomos descentralizados. 4. Atribuir deberes, responsabilidades y competencias a los gobiernos autónomos descentralizados. 5. Modificar la división político-administrativa del país, excepto en lo relativo a las parroquias. 6. Otorgar a los organismos públicos de control y regulación la facultad de expedir normas de carácter general en las materias propias de su competencia, sin que puedan alterar o innovar las disposiciones legales" (énfasis añadido).

19 Art. 133.- "Las leyes serán orgánicas y ordinarias. Serán leyes orgánicas: 1. Las que regulen la organización y funcionamiento de las instituciones creadas por la Constitución. 2. Las que regulen el ejercicio de los derechos y garantías constitucionales. 3. Las que regulen la organización, competencias, facultades y funcionamiento de los gobiernos. autónomos descentralizados. 4. Las relativas al régimen de partidos políticos y al sistema electoral. [...] Las demás serán leyes ordinarias, que no podrán modificar ni prevalecer sobre una ley orgánica” (énfasis añadido). 
parece confundir a la reserva de ley ordinaria mínima con la reserva de ley orgánica máxima. Además, es importante notar que la amplitud del numeral 1 del artículo 132 y del numeral 2 del artículo 133 de la Constitución -esto es, la regulación del ejercicio de los derechos y garantías constitucionales mediante ley ordinaria y ley orgánica- lleva a que, con una interpretación amplia, prácticamente cualquier materia pueda ser regulada mediante ley orgánica u ordinaria, sin contravenir la reserva normativa constitucionalmente establecida.

\section{Principio de especialidad}

El principio de especialidad implica que, en caso de contradicción entre dos normas, deberá prevalecer la norma especial frente a la norma general. Evidentemente, el principio de especialidad es aplicable para resolver antinomias entre normas de la misma jerarquía. Caso contrario, el conflicto se resolvería por medio de la aplicación del principio jerárquico y no sería necesario recurrir al principio de especialidad.

La dificultad de este principio radica en determinar cuál es la norma especial, pues ninguna norma jurídica puede considerarse especial por sí misma, sino que su especialidad debe determinarse en función de la norma con la cual se la contrasta y los hechos que se pretenden regular. De hecho, incluso dentro de un mismo cuerpo normativo pueden existir disposiciones que se consideren especiales respecto a otras generales del mismo cuerpo normativo (Código Civil, 2005, art. 12) ${ }^{20}$.

20 Un ejemplo claro lo encontramos en el propio Código Civil, respecto de los artículos 696 y 1814. Por un lado, el artículo 696 es una norma general sobre la tradición, que señala que esta puede estar sujeta a una condición, y que permite que el vendedor se pueda reservar el dominio de la cosa hasta el pago del precio. Por otro lado, el artículo 1814 es una norma especial al contrato de compraventa, que prescribe que la reserva de dominio hasta el pago del precio no surte efectos (la norma establece que la falta de pago del precio únicamente habilita el derecho a resolver el contrato o a demandar su cumplimiento forzoso). En este orden de ideas, para determinar si en el contrato de compraventa cabe reservarse el dominio hasta el pago del precio, por el principio de especialidad el intérprete debería aplicar el artículo 1814 y concluir que no. 
Aun cuando el legislador denomine o incluya en la denominación de una norma la palabra "especial", aquello no implica que sus disposiciones deban ser consideradas especiales de forma absoluta para efectos de aplicación del principio de especialidad, pues como quedó indicado, la especialidad de una norma es relativa a con qué norma se la compara, pudiendo ser en algunos casos general respecto a la norma con la cual se compara y en otros resultar especial.

En razón de lo indicado, cuando se analiza una ley que contiene varias disposiciones, tampoco es posible señalar que todas las disposiciones de esa ley son especiales frente a las disposiciones de otra ley que se consideran generales, sino que el análisis debe realizarse caso por caso, siendo posible que ciertas normas de la ley analizada resulten "especiales" frente a las normas de otra y viceversa. En este sentido, se ha dicho que un problema que debe resolverse en cada caso concreto respecto del principio de especialidad es "el de la relatividad del criterio general-especial, en tanto que una norma A puede ser general con respecto a una norma B, pero, a su vez, especial con respecto a una norma C" (Tardío, 2003, p.200).

\section{Principio cronológico}

Este principio implica que la norma posterior prevalece sobre la anterior y parte de la lógica elemental de que, si el legislador promulga una nueva normativa, es con el propósito de modificar la anterior y que prime sobre ésta.

No resulta coherente pensar que una nueva normativa no pueda ser aplicada por la existencia de normas previas que la contradicen, pues aquello, como señala Bobbio (2012), “obstaculizaría el progreso jurídico y la gradual adaptación del derecho a las exigencias sociales" (p. 208). En este orden de ideas, la doctrina ha reconocido que si el legislador "elabora una norma que entra en conflicto con otra anterior es porque ha decidido conscientemente modificar la regulación de una materia de tal modo que será la más reciente la que deba prevalecer" (Ezquiaga, 2010, p.28). De lo dicho se desprende que el principio cronológico se relaciona directamente con la derogatoria 
tácita de una norma, pues es precisamente cuando se expide una norma posterior que contradice a la anterior que se dice que ha operado una derogatoria tácita.

Al igual que ocurre con el principio de especialidad, el criterio cronológico es aplicable cuando se contrastan dos normas de la misma jerarquía que son competentes para regular esa materia, pues si se trata de dos normas de distinta jerarquía normativa, la antinomia quedará resuelta con la aplicación del principio jerárquico. Justamente, en palabras de Bobbio (2012), "el criterio cronológico vale como criterio de elección entre dos normas puestas en el mismo plano, más cuando dos normas están colocadas en planos diferentes, el criterio natural de elección es el que nace de la misma diferencia de planos" (p.208).

\section{Prelación en la aplicación de los principios de resolución de antinomias}

Una vez analizados los cuatro criterios o principios para resolver las antinomias que se presentan en el ordenamiento jurídico ecuatoriano, corresponde determinar si existe algún tipo de prevalencia entre los mencionados principios, pues puede ocurrir que en función del principio que aplique el intérprete, cambie el resultado en cuanto a qué norma prevalece sobre la otra. Para Bobbio (2012), la respuesta al planteamiento realizado "depende del hecho de si hay o no reglas tradicionalmente admitidas para la solución del conflicto entre criterios, así como existen reglas admitidas para solucionar el conflicto entre normas" (p.207).

\section{El principio de competencia y el principio jerárquico}

El artículo 425 de la Constitución de 2008 establece un orden jerárquico de aplicación de las normas y de forma expresa dispone que "en caso de conflicto entre normas de distinta jerarquía, la Corte Constitucional, las juezas y jueces, autoridades administrativas y servidores públicos, lo resolverán mediante la aplicación de la norma jerárquica superior". Aquello implica que el criterio jerárquico 
para resolver antinomias normativas tiene rango constitucional y, en principio, prevalecería sobre el resto de criterios.

Sin embargo, es necesario advertir que el inciso final del propio artículo 425 de la Constitución de 2008, prescribe que "la jerarquía normativa considerará, en lo que corresponda, el principio de competencia [...]", lo que implica que la aplicación del principio de competencia, frente a una antinomia, puede derivar en que una norma inferior prevalezca sobre una de superior jerarquía normativa, por ser competente para regular una determinada materia. Un ejemplo bastante ilustrativo consiste en un posible conflicto entre una norma regional ${ }^{21}$ y una ley, pues, en caso de que exista una antinomia entre estas normas, el intérprete deberá establecer qué norma es competente para regular la materia en que se produce la incompatibilidad. Dicha competencia deberá determinarse en función de las reservas normativas constitucionalmente establecidas y, en caso de que la materia deba ser regulada por una norma regional, esta norma, a pesar de ser jerárquicamente inferior, podría prevalecer sobre la ley por el principio de competencia.

En consecuencia, es posible afirmar que el primer criterio aplicable para la solución de antinomias en el Ecuador debe ser el de competencia. En caso de que este criterio no permita resolver el conflicto - ya sea porque no existe una reserva normativa que abarque la materia en la cual se produce la contradicción de las normas o porque ambas normas son competentes para regular la materia- se deberá aplicar el principio de jerarquía.

\section{El principio cronológico y del principio de especialidad}

Contrario a lo que ocurre con los principios de competencia y jerarquía, los principios de especialidad y cronológico no tienen

21 Al respecto, cabe señalar que la Constitución les atribuye a los gobiernos autónomos regionales la competencia exclusiva para expedir normas regionales (2008, art. 262). 
sustento constitucional sino tan solo legal ${ }^{22} \mathrm{y}$, por ello, es mucho más complejo determinar cuál prevalece sobre el otro.

Respecto de las regulaciones que contiene el Código Civil sobre solución de antinomias, es necesario destacar que dicho cuerpo normativo es una ley ordinaria que regula esencialmente las relaciones entre privados, pero que dada la tradición civilista del Ecuador, contiene una serie de principios que no corresponden al ámbito de su regulación ${ }^{23}$. Por lo mismo, es importante aclarar que sus disposiciones son meramente referenciales en cuanto a la solución de una antinomia entre leyes que regulan aspectos de derecho público.

El conflicto entre los principios de especialidad y el cronológico se produce especialmente cuando se promulga una ley general posterior que contradice una ley especial anterior y existen varios criterios en cuanto a cuál puede ser su solución. Si bien tradicionalmente se ha dicho que el principio de especialidad debería ser considerado antes que el cronológico, actualmente la doctrina cuestiona dicha afirmación, pues cuando el legislador expide una norma general posterior se infiere que pretende unificar el régimen jurídico respecto de esa materia y eliminar excepciones previstas en leyes especiales. $\mathrm{Al}$ respecto, se ha dicho que:

Los criterios de la cronología y de la especialidad entrarían en conflicto si una norma posterior y general es incompatible con otra norma anterior y especial. Según el criterio de la cronología prevalecería la poste-

22 Estos principios cuentan con regulación de índole legal en las siguientes normas: (i) artículo 3 numeral 1 de la LOGJCC; (ii) artículo 12 del Código Civil -norma que consagra el principio de especialidad-; (iii) artículo 37 del Código Civil -norma que recoge los postulados del principio cronológico-.

23 En palabras de Juan Montaña Pinto (2012), “[n]o se debe olvidar que la estructuración del llamado "sistema de fuentes" en los países tributarios del sistema jurídico romano germánico, se hizo mediante el derecho privado, particularmente del Código Civil por ser este el "texto" y el "lugar" donde se establecían los criterios de interpretación, armonización y ordenación de las distintas normas que integraban el ordenamiento jurídico" (p. 17). 
rior y según el de la especialidad la especial. Este conflicto es de difícil solución y no hay una postura unánime al respecto. Por un lado, puede afirmarse que si el legislador ha dictado una regulación general que contradice otra anterior especial es porque deseaba terminar con ese trato excepcional, ya que, de lo contrario, en la nueva norma general hubiera incluido una salvedad expresa en relación con la situación anterior. Pero, por otro, pueden invocarse argumentos de justicia para mantener la regulación especial aunque sea anterior. En definitiva, será el órgano jurisdiccional el que deberá decidir en cada caso, aunque en los Tribunales puede apreciarse una cierta línea jurisprudencial en favor del criterio de la especialidad. Esta solución es admisible, por supuesto, siempre que las dos normas en conflicto tengan el mismo rango jerárquico, ya que de lo contrario prevalecerá la superior aunque se trate de la anterior o de la general (Ezquiaga, 2010, 34-35) (énfasis añadido).

Respecto de la prevalencia del principio de especialidad sobre el cronológico, se ha sostenido que:

Esta regla, por otra parte, debe ser tomada con cierta cautela, ya que tiene un valor menos perentorio que el de la regla precedente [en referencia al principio de jerarquía]. Se diría que lex specialis tiene menos fuerza que la lex superior, y que por consiguiente, su victoria sobre la lex posterior es más discutida. Sin embargo, para hacer afirmaciones más precisas en este campo, es necesario disponer de una amplia casuística (Bobbio, 2012, 208).

También se ha mencionado en cuanto a esta problemática, que es necesario distinguir dos situaciones: “[...] a) si la ley posterior es particular, no hay duda que constituye una modificación parcial, y b) si la ley posterior es general, puede ser que derogue totalmente la anterior, o bien que la deje insubsistente a título de excepción, según el caso" (Monroy Cabra, 2003, 178).

En nuestro criterio, un eventual conflicto entre el principio de especialidad y el principio cronológico, la intención del legislador es sustancial para determinar la prevalencia de un principio frente a otro. Al respecto, la Corte Constitucional italiana (Sentencia 29/1976, 1976), citada por Guastini (1999, p.444), señaló que: 
[...] en la hipótesis de sucesión de una ley general a una ley especial, no es verdadera en lo absoluto la máxima de que lex posteriori generalis no derogar priori speciali: ya que los límites de dicho principio van, en efecto, de vez en vez, siempre verificados en la medida de la intención del legislador. Y no se excluye en concreto la interpretación de la voluntas legis, de la que depende la solución del indicado problema de sucesión de normas, evidencie una amplitud de la ley general posterior, tal que no tolere excepciones, ni siquiera de parte de leyes especiales: las cuales quedan, de ese modo, tácitamente abrogadas (énfasis añadido).

El Código Civil ecuatoriano respecto a este conflicto establece que "la ley especial anterior no se deroga por la general posterior, si no se expresa" (2005, art. 39), es decir que admite la posibilidad de que el principio cronológico prevalezca sobre el principio de especialidad, pero instituye una condición: la ley general posterior debe manifestar que deroga a la especial anterior. La cuestión que debe plantearse frente a esta disposición del Código Civil es si una derogación general expresa ${ }^{24}$ cumple esta condición y si es suficiente para que la norma general posterior prevalezca sobre la especial anterior.

Al respecto, es claro que si lo que busca el legislador es terminar todo tratamiento excepcional y por ende establecer una regulación general que derogue toda disposición anterior que se le oponga, basta con que incluya una disposición derogatoria general en tal sentido, sin necesidad de que mencione el nombre de la ley o el número del articulado, para considerar que esa disposición ha sido tácitamente derogada y por ende, en aplicación del principio cronológico, la norma posterior prevalezca sobre la anterior.

24 Un ejemplo de una derogación general expresa es el siguiente: "Esta Ley deroga toda norma especial o general que se le oponga”. Esta fórmula se utiliza en la disposición General Cuarta de la Ley para la Reforma de las Finanzas Públicas, publicada en el Registro Oficial No. 181-S de 22 de diciembre de 1999. Incluso, cabe señalar que la misma Constitución de 2008 contiene una Disposición Derogatoria General, en virtud de la cual se deroga la Constitución del año 1998, así como "toda norma contraria a esta Constitución". 
Resulta una interpretación extremadamente literal y asistemática respecto a todo el ordenamiento jurídico ecuatoriano, el sostener que solamente una ley general posterior puede prevalecer sobre una especial anterior, si la ley general hace mención expresa a la denominación de la ley especial y proclama su derogación. La referida afirmación no considera la intención del legislador de unificar el tratamiento jurídico de una determinada situación, que en muchos casos es expresa, y desecha por ende la posibilidad de que la ley general posterior derogue expresamente toda disposición especial que se le oponga, sin necesidad de mencionar los nombres de las leyes derogadas.

Desde nuestro punto de vista, cuando exista forma de determinar que la intencionalidad del legislador es la unificación de un determinado régimen jurídico y la norma contenga una disposición derogatoria general, aun cuando se trate de una norma general posterior, es razonable sostener que prevalece sobre la norma especial anterior.

Por ejemplo, si se decide unificar y regular todos los procedimientos judiciales en un solo Código de Procesos y esta intención es expresamente manifestada por el legislador, tanto durante la discusión del nuevo Código, como en los considerandos y texto del mismo, aun cuando no se derogue expresamente un procedimiento judicial establecido en una ley especial anterior, el intérprete puede llegar a la conclusión de que dicho procedimiento establecido en la ley especial ha sido derogado tácitamente por la ley general posterior y por ende no es aplicable. En el ejemplo expuesto, la ley general posterior derogaría tácitamente a la especial anterior ${ }^{25}$.

En tal sentido, nos apartamos del criterio de cierto sector de la doctrina, que sostiene que solamente si se menciona de forma expresa a la ley

25 En el Ecuador se vive un proceso de esta naturaleza con la expedición del Código Orgánico General de Procesos promulgado el 22 de mayo de 2015 en el Registro Oficial No. 506, el cual unifica toda la actividad procesal en todas las materias salvo la constitucional, electoral y penal. Los procedimientos judiciales previstos en normas especiales anteriores, aun cuando no hayan sido expresamente derogados, son considerados por los jueces como tácitamente derogados. 
especial como derogada en la ley general posterior, ésta podrá prevalecer sobre la especial. Sin embargo, parece ser que es esta posición la que se ha adoptado en nuestro país. Los pronunciamientos del Procurador General del Estado sobre las disposiciones derogatorias del Código Orgánico Administrativo (COA) son un claro ejemplo de aquello.

Al respecto, es necesario recordar que el COA representa el intento de superar la "no codificación" del Derecho administrativo y que, por lo mismo, fue expedido con el fin de regular de manera uniforme e integral el ejercicio de la función administrativa (Guerrero, 2019, 40-41). La uniformidad que se buscó lograr con el COA se refleja no solo en el artículo 1 de dicho cuerpo normativo ${ }^{26}$, sino también en sus disposiciones derogatorias. En este sentido, para que exista uniformidad en la regulación del procedimiento administrativo, la Disposición Derogatoria Primera del COA prescribe que se derogan "todas las disposiciones concernientes al procedimiento administrativo, procedimiento administrativo sancionador, recursos en vía administrativa, caducidad de las competencias y del procedimiento y la prescripción de las sanciones que se han venido aplicando" (COA, 2017). Por su parte, la Disposición Derogatoria Novena contiene una derogación general expresa, en virtud de la cual se derogan "otras disposiciones generales y especiales que se opongan al presente Código Orgánico Administrativo" (COA, 2017) (énfasis añadido).

El Procurador General del Estado, en el año 2019, se pronunció sobre dos consultas referentes a la derogatoria tácita de procedimientos administrativos especiales contenidos en normas anteriores al COA. En ambas consultas, consideró que la derogación general contenida en el COA no es suficiente para derogar tácitamente las normas especiales anteriores a dicho cuerpo normativo. En materia de salud, el Procurador observó que la Ley Orgánica de Salud y el COA contienen normas incompatibles respecto del procedimiento administrativo sancionador, pero determinó que las disposiciones de la referida ley no fueron derogadas por el COA en los términos del

26 Art. 1.- "Este Código regula el ejercicio de la función administrativa de los organismos que conforman el sector público". 
artículo 39 del Código Civil (Oficio PGE No. 02145, 2019). El Procurador sostuvo el mismo razonamiento en materia de derecho de la competencia, al señalar que el COA no derogó, ni expresa ni tácitamente, el procedimiento sancionador especial establecido en la Ley Orgánica de Regulación y Control de Poder de Mercado (Oficio PGE No. 06578, 2019).

En nuestro criterio, estas decisiones, sustentadas en el Código Civil (ley ordinaria de derecho privado), vacían el contenido de las disposiciones derogatorias del COA y desconocen la intención del legislador al expedir este cuerpo normativo. Por lo mismo, consideramos que sí se deberían entender tácitamente derogadas aquellas normas especiales anteriores a la vigencia del COA.

Desde nuestro punto de vista, la afirmación de que la norma general posterior no modifica ni deroga la norma especial anterior no es absoluta y, por lo tanto, es necesario un riguroso análisis casuístico para determinar la forma en que debe resolverse la antinomia, siendo razonable y jurídicamente correcto que, en determinados casos, prevalezca la norma general posterior.

\section{Conclusiones}

A lo largo de este artículo, hemos buscado enfocar a la derogatoria tácita de una norma como un problema de interpretación, que genera una antinomia. Para solucionar antinomias, existen varios criterios, previstos tanto a nivel constitucional como legal. En un primer momento, el intérprete deberá aplicar el principio de competencia y de jerarquía, los cuales tienen sustento constitucional. Por su parte, los principios de especialidad y de cronología deben aplicarse con posterioridad a los dos primeros. Sin embargo, ante la falta de un criterio claro sobre cuál de los dos principios debe prevalecer, consideramos indispensable que el intérprete realice un minucioso análisis casuístico, en el cual deberá considerar, particularmente, la intención del legislador. 


\section{Referencias Bibliográficas}

Asamblea Nacional del Ecuador. Código Civil. (24 de junio de 2005). Registro Oficial Suplemento 46.

Asamblea Nacional del Ecuador. Código Orgánico Administrativo. (07 de julio de 2017). Registro Oficial Suplemento 31.

Asamblea Nacional del Ecuador. Ley Orgánica de Garantías Jurisdiccionales y Control Constitucional. (22 de octubre de 2009). Registro Oficial Suplemento 52.

Bobbio, N. (2012). Teoría General del Derecho. Bogotá, Colombia: Temis.

Constitución de la República del Ecuador [Const.]. (2008). Recuperado de https://www.lexis.com.ec/

Constitución de la República del Ecuador [Const.]. (1998). [Derogada] Recuperado de https://www.lexis.com.ec/

Corte Constitucional de Colombia. (10 de septiembre de 2014) Sentencia C-668/14. [MP Luis Guillermo Guerrero Pérez].

Corte Constitucional del Ecuador. (21 de marzo de 2013) Sentencia No. 001-13-SIA-CC. [MP Fabián Marcelo Jaramillo Villa]. Registro Oficial Suplemento 933.

Ezquiaga Ganuzas, F. (2010). Conflictos e interpretación jurídica. Michoacán, México: Cuadernos de Divulgación sobre Cultura de la Legalidad, Tribunal Electoral del Estado de Michoacán.

Gascón Abellán, M. (1994). Cuestiones sobre la derogación. Revista Doxa, N. 15-16, 845-859. DOI: 10.14198/DOXA1994.15-16.42

Guastini, R. (1999). Antinomias y lagunas. Revista Jurídica Anuario del Departamento de Derecho de la Universidad Iberoamericana, 29, 437-450. 
Guerrero, F. (2019). Nueva visión del Derecho Administrativo: Sustentada en el Código Orgánico Administrativo y normativa conexa. Quito, Ecuador: Cevallos.

Henríquez, M. (2013). Los jueces y la resolución de antinomias desde la perspectiva de las fuentes del derecho constitucional chileno. Estudios constitucionales, 11(1), 429-476. DOI: 10.4067/S0718-52002013000100012

Monroy, M. (2003). Introducción al Derecho. Bogotá, Colombia: Temis.

Montaña, J. (2012). Teoría Utópica de los Derechos. Quito, Ecuador: Corte Constitucional del Ecuador, Centro de Estudios y Difusión del Derecho Constitucional.

Prieto, L. (2002). Observaciones sobre las antinomias y el criterio de ponderación. Diritto \& Questioni Pubbliche, 2, 97-114.

Procuraduría General del Estado. Oficio No. 06578. (11 de noviembre de 2019). Registro Oficial 111.

Procuraduría General del Estado. Oficio No. 02145. (03 de enero de 2019). Registro Oficial 436.

Tardío, J. (2003). El principio de especialidad normativa (LEX SPECIALIS) y sus aplicaciones jurisprudenciales. Revista de Administración Pública, 162, 189-225.

Torré, A. (2009). Introducción al Derecho. Buenos Aires, Argentina: AbeledoPerrot.

Tribunal Constitucional del Ecuador. (19 de noviembre de 2003) Resolución No. 030-2003-TC. Registro Oficial 223. 